\section{FOUNDATIONS OF NEUROPSYCHIATRY}

By Stanley CoBb, A.B., M.D., D.Sc. 6th edition. Pp. ix +305 . London: Baillière, Tindall \& Cox Ltd. 1958. 40s.

This sixth edition, a work well known to psychiatrists on both sides of the Herring Pond, continues to provide essential facts in neuropsychiatry in a concise, well-planned volume. Apart from bringing the material up to date, two new subjects receive attention in this work-those of neurochemistry and central modulation of sensory perception, both of which have been subjects of important symposia recently. The discussion on pain has been considerably enlarged and now appears in a relevant context in a number of chapters. As the most important single topic in medicine, it has received all too little attention in the past; now it is treated at anatomical, neurological and psychological levels. It is a pity that Professor Cobb has omitted the work by Hardy, Wolff and colleagues on pain threshold. Their findings that, for example, the anxious individual experiences pain earlier and more intensely than does the placid or depressed patient undergoing identical physical stimulation has important implications, not only in psychiatry, but in general practice, where pain is the most frequent symptom and over one third of the patients are suffering from some form of psychological stress. Both bibliography and index are rather short for a book of this size and importance, but they are not inadequate and selection has been good. D.P.M. students will find this an extremely useful text, for with this new edition it remains the best introduction to the subject in print today.

\section{L.R.C.H.}

\section{PHYSICS FOR THE ANAESTHETIST}

\section{Including a Section on Explosions}

By Sir Robert Macintosh, M.A., D.M., F.R.C.S.E., F.F.A., R.C.S., William Mushin, M.A., M.B., B.S., F.F.A., R.C.S., and H. G. EPstein, M.A., Ph.D., F.F.A., R.C.S. Second Edition. Pp. xi +443 , illustrated. 1958. 6os. Oxford: Blackwell Scientific Publications.

The Second Edition of the deservedly popular ' Physics for the Anaesthetist' makes its appearance with Dr. H. G. Epstein as a third co-author. In addition to the many valuable pages which he contributed to the First Edition, Dr. Epstein has written a completely new Section on Explosions, $\vec{\circ}$ with a wealth of technical detail concerning their. causes and prevention in relation to anaesthetic $\vec{\omega}$ apparatus and operating theatres. In all, this ${ }^{\circ}$ Section adds 112 pages to the original text. There are some other minor additions, including a very 3 clear treatise on the Flow of Fluids. With just a quarter of the book devoted to this single subject, it $\$$ is pertinent to ask How common are anaesthetic ${ }_{0}$ explosions? Surely they represent a very small fraction of all the many possible accidents of 0 anaesthesia; particularly must this be so today, i with the predominant trend away from the use of inflammable agents. Considered as a monograph, Dr. Epstein's Section is masterly, but it is difficult $\vec{\oplus}$ to escape the impression that his theme has got a $\mathbb{D}$ little out of hand. In contrast, halothane, the most potent and completely non-inflammable addition to the anaesthetist's armamentarium, receives only passing mention. Some descriptive materigi, matter and plates, retained from the previous $\overrightarrow{0}$ edition, would seem more appropriate to a textbowk on the history of anaesthetic apparatus (many of the illustrations are found in Duncum's 'De-O velopment of Inhalation Anaesthesia'*) and, although they add a certain wayward charm, could scarcely be held to be essential to the purpose of ${ }_{0}^{\beth}$ this book. In all other respects there is evidence of $\stackrel{\mathbb{Q}}{\varrho}$ meticulous editing and revision, and the lucidity $\Rightarrow$ with which the authors present the physicalo principles underlying the anaesthetist's craft could scarcely be bettered. The many beautiful dia-P grams by Miss M. McLarty and Miss M. Beck hardly need their explanatory legends. An im-윽 proved binding and more elegant format add to the attractiveness of this edition.

At 60 s. this edition is more likely to attract the medical librarian than the private purchaser.

H.L.T

* 'Development of Inhalation Anaesthesia.' Duncum, Barbara M. 옹 1946. Oxford University Press.

' THE GLAUCOMAS '

By H. Saul Sugar, M.D., F.A.C.S. Second edition. Pp. viii $+{ }_{5}$ I6. London: Cassell and Company Limited. I957. I05s.

This book, now in its second edition, appears at a most appropriate time. The whole concept of the aetiology of the primary Glaucomas is undergoing 